\title{
A Novel Collaborative Management Theory based Shipping and Forwarder Management Platform
}

\author{
Zhongdai $\mathrm{Wu}^{1}$, Minghai $\mathrm{Ye}^{1}$, Yinyin $\mathrm{Wang}^{1}$ and $\mathrm{Jin} \mathrm{Liu}^{2}$ \\ ${ }^{1}$ School of Economics and Management, Tongji University, Shanghai, 200092 \\ ${ }^{2}$ Shanghai Maritime University, Shanghai, 200135 \\ \{wzd,mhy,yyw\}@cnshipping.com; jinliu@shmtu.edu.cn
}

\begin{abstract}
Shipping and forwarder management platform is not only an important platform for shipping companies to operate business, but also a technical guarantee for service efficiency improvement. In order to solve current realistic problem such as low-efficiency in resource allocation, difficulty in head-office management, and inaccuracy and delay of data sharing, a shipping and forwarder management platform (SFMP) fitting for international container shipping logistical companies based on collaborative management theory is proposed. People collaboration, information collaboration, process collaboration and application collaboration are core of management platform. This paper proposes an effective collaborative management theory for shipping industry and presents how to constructed a comprehensive systematic management platform covering shipping business and forwarder business. Case study has proved that the proposed platform could improve 10\%-25\% operation efficiency, enhance collaborate level and strengthen shipping companies' competitiveness in global market
\end{abstract}

Keywords: Collaborative management; Shipping and forwarder management platform; Shipping companies; Informationization

\section{Introduction}

Since china's entry into WTO, the rapid development of shipping industry has brought development opportunities to shipping service industry - international shipping agency industry and marine freight forwarding industry; and meanwhile, the competition among shipping agency enterprises has become more and more fierce. The development of core competitiveness has become an inevitable choice [1] for shipping agency enterprises in our country. Under the premise of increasingly sophisticated information technology and network technology, modern shipping service enterprises raise a higher requirement on the information system, i.e. to reflect every link of logistics and changes of the unpredictable market timely, accurately and comprehensively, and provide customers with safe, rapid, allaround, and multi-level information services based on the whole it frame. However, most shipping agency systems and freight forwarding system within the industry encounter the problems of low efficiency, resource wastes, and inadequate monitoring and management due to the lack of unified planning at the initial stage of development and limited timeliness and accuracy data sharing. With the rapid expansion of marine transport businesses, these problems have hindered the further development of shipping service enterprises on the international and domestic markets. the authors believe that these problems, to a large extent, are attributed to the absence of direction by Collaborative management theory in the planning and design of the management platform, which makes it difficult to achieve the most effective 
sharing, integration, allocation and optimization of "people, information, procedure, and application" in enterprises. In addition, the integration of shipping agency and freight forwarding businesses is provided with necessity, which is in favor of unified scheduling, comprehensive management, and data processing if considered from the perspective of enterprises' business requirements. Moreover, the integration of the two crucial links-shipping agency and freight forwarding in the supply chain with information system contributes to the linkage in the whole business procedure. Therefore, the integration of shipping agency and freight forwarding businesses and construction of an integrally planned shipping agency and freight management platform under the direction of Collaborative management is of great practical significance.

Collaborative theory was produced at the early 1990s. Synergy refers to the process or capability of coordinating two or more different resources or individuals to achieve a certain target consistently. It involves the cooperation among not only people, but also different application systems, data resources, and equipment. American strategic management expert, H.Igor Ansoff first put forward the conception of synergy in his book "Corporate Strategy": cooperation among business units of an enterprise can make the total enterprise value greater than the simple totaling of values of all independent constituent parts (Du Dong, 2008a) [8]. Du Dong, believes that the Collaborative management refers to the coordination or operation of linking various resources, and eliminating various hinders and barriers generated in the coordination process, to accomplish the common task or target. The system based on Collaborative management comprises four elements: people, information, procedure, and application, wherein the synergy of people is the core, while the synergy of information, procedure and application all serve the efficient synergy of people (Du Dong, 2008b) [9].

\section{Related Work}

Currently, most Chinese and overseas studies on shipping agency and freight forwarding platform probe into the construction ideas in term of technology, and focus on the vital function of a certain technology, such as digital logistics technology (Cheng Qingsheng, 2008) [2], unified modeling language (Lin Hong, 2000) [3], and so on, in improving platform operating efficiency, but rarely explore in depth the platform construction scheme combining with the management theory; or only discuss the construction though and design scheme of freight forwarding system from the perspective of freight forwarder enterprises, such as the study made by Gong Luyang (Shenyang, 2009) on the solution to freight logistics information system [4], and information system construction scheme [5] put forward by Qing Bo and Yu Jinshan (2009) by taking large-scale freight forwarder enterprises as the objectives.

These studies do not plan and design the management platform by putting shipping enterprises and freight forwarding enterprises under the same framework. Moreover, in the studies on Collaborative management system, the current research objects are mostly manufacturing enterprises, such as the Study on Single Piece Small-lot Production Management System by Collaborative Management Theory (Li Liqing, Lu Hai et.al., 2011) [6], Network Logistics Support System of Medium- and Small-sized Enterprises (Yousheng, 2010) [7], and so on, while studies on shipping enterprises are relatively few. In conclusion, the construction of a comprehensive management platform involving shipping agency enterprises and freight forwarding enterprises based on the management theory and IT technology and taking shipping enterprises as the research background is very necessary.

Theoretically, the construction of a shipping agency and freight forwarding management platform based on the Collaborative management is conducive to extending the application scope of Collaborative management theory to the shipping industry, promoting the comprehensiveness and comprehensiveness of information system design research of 
shipping enterprises, and enabling not only the technical superiority but also the management theory depth of information system design. In practices, it helps shipping enterprises to conduct optimal configuration of internal resources, achieve advantage complementation, face up changes of market environment accurately, rapidly and efficiently, and provide highquality services to customers around the globe. Therefore, it has great theoretical and practical significance.

The rest of this paper is organized as follows, in Section 3, we present the design and architecture of the proposed shipping agency and freight management platform; in Section 4, we present the real world application cases of the proposed system; and then the conclusion remarks are made in Section 5.

\section{Design Methodology of SFMP}

The shipping agency and freight forwarding management platform (SFMP) presented in this section is geared to the needs of international container shipping logistics enterprises in rapid development. This platform covers the whole process of production, marketing, and management of sea transportation container liners, and can meet not only the requirements of business operations by port enterprises, but also the requirements of shipping headquarters in aspects of statistic analysis, business settlement, and decision management.

\subsection{Principles for Development of Shipping Agency and Freight Forwarding Management Platform Based on Collaborative Management}

In order to achieve the "people synergy, information synergy, procedure synergy, and application synergy", the development of shipping agency and freight forwarding management platform must stick to the principles of normality, extensibility, transferability, and maintainability.

1) Normality: the principles of "unified leadership, unified planning, unified standard, stepby-step implementation, and level-to-level administration" must be adhered to in the development of the platform. The system construction shall not only meet relevant policies and industrial standards, but also abide by the guiding principle of standardization and integration, to guarantee every business module in the platform is tightly integrated in the management platform.

2) Expandability: the development of the management platform shall not only take into account the current cooperatives of business modules, but also give considerations to the cooperatives with the business possibly be developed in the future, namely consider the extension possibility of business procedure, system, and management mode in the future. The system development and design shall be provided with extensibility and the application software shall have a relatively high modularization degree. As to the function or component of the subsystem with relatively high requirement on sharing in business application, subsystem design technology may be adopted to form relatively independent standard module.

3) Transferability: to utilize the existing resources and application programs in the management platform cooperatively, it is required to guarantee the transferability of the platform in different systems, application programs, areas, and various operating systems, as well as on different middleware platforms. Therefore, unified modeling language and design pattern unanimously recognized by the national software industry shall be adopted in the design. 
4) Maintainability: information synergy is the basic element for the Collaborative management platform, and the safety and maintainability of data are the key of information synergy. Therefore, the platform development shall abide by relevant information safety standards and the system shall provide multi-model, multi-level, and multi-channel security measures to make sure the permanent security of data. The foundation platform system is administrated from aspects of data storage and transmission, user management and authentication, user application module, data use authority permission assignment, and so on, to guarantee the safe operation of the system.

\subsection{System Architecture and Major Components}

The shipping agency and freight forwarding platform studied in this paper adopts a CSS multi-layer architecture; the client-side employs the WinForm interface developed by C\# to make the interface more flexible and easier to use; the intermediate layer uses .Net to guarantee the stable and rapid running of the system; the database adopts Oracle, making data safe and stable. The framework fully embodies the $4 \mathrm{~S}$ principle (Speed, Stable, Safe and Simple).

1) Client-side (presentation layer):

The presentation layer is used to display data and receiving the data inputted by the user, in order to provide an interactive operation interface to users. The shipping agency and freight forwarding management platform based on Collaborative management adopts a unified function icon display interface integrating the shipping agency and freight forwarding functions, which enables users to select various functions conveniently, realizes quick, intuitional, and simple operations, and improves the cooperative work efficiency of shipping agency enterprises and freight forwarding enterprises.

2) Business Logic Layer

The business logic layer is driven by the events of the presentation layer and finishes the assembly, calculation, and processing of data before providing the processed data to the presentation layer or data layer. The business logic layer of the platform uses the ServiceOriented Architecture (SOA), links the shipping agency function and freight forwarding function by the well-defined interface between services, and develops the general functions for shipping agency and freight forwarding by the same class; it achieves the loose coupling of business logic to the maximum extent, is configurable and modular with high reliability of program and a small amount of development workload, and brings shipping agency and freight forwarding enterprises with better flexibility to construct application programs and business procedures.

\section{3) Data Access Layer}

The data access layer provides standard interfaces to achieve the function of data access, is directly connected with the ORACLE database, and carries out addition, deletion, updating, search, etc. of data. The ORACLE database is a large relational database, which provides shipping agency and freight forwarding enterprises with an efficient, stable, and safe management of their mass data. Based on the design that is described above, the system encapsulates the public components in a set of utility class library which mainly comprises XML analysis and generation, HTTP communication, encryption algorithm, and so on. The platform architecture is shown in Figure 1. 


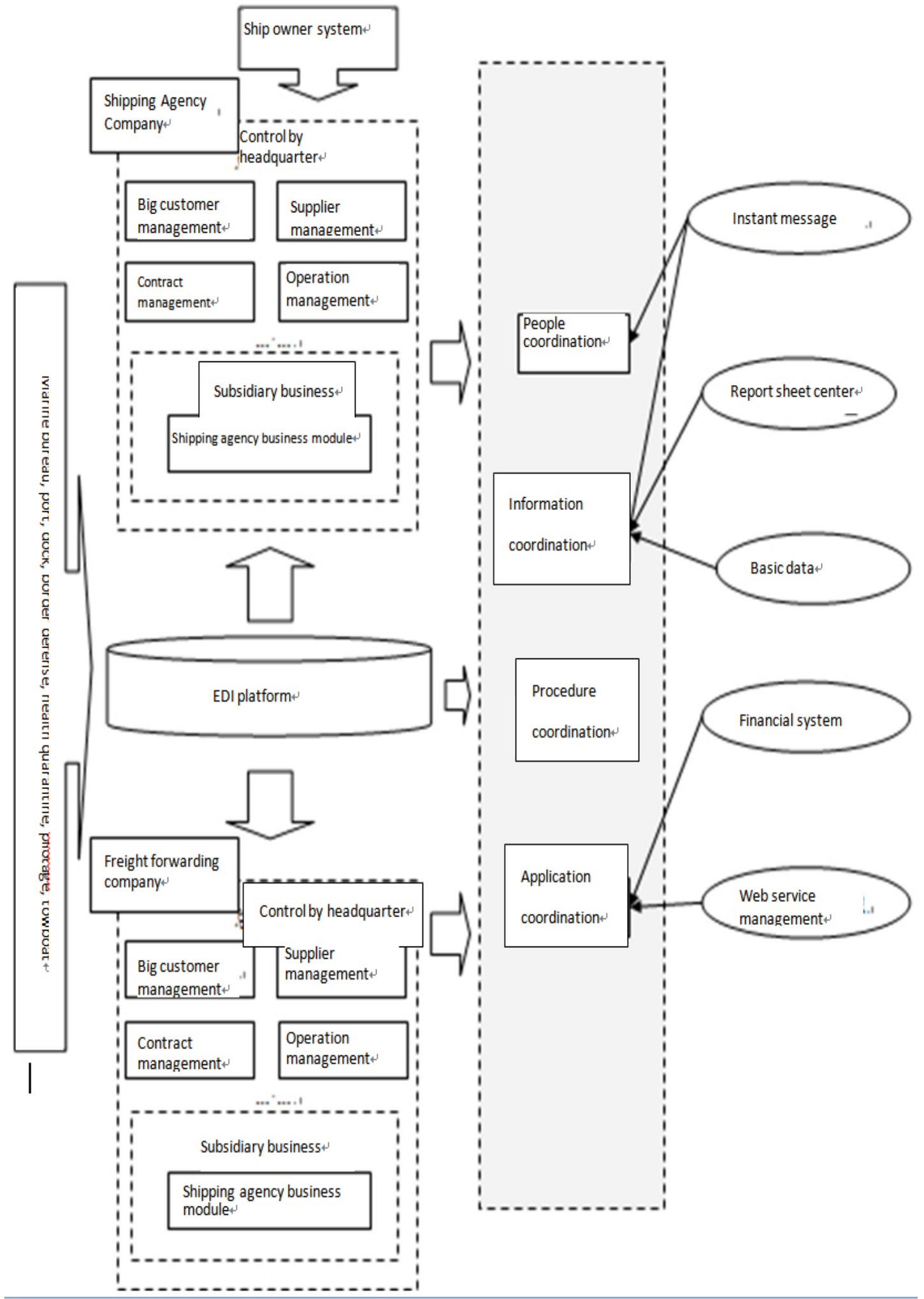

Figure 1. Construction Diagram of Shipping Agency and Freight Forwarding Management Platform Based on Collaborative Management 


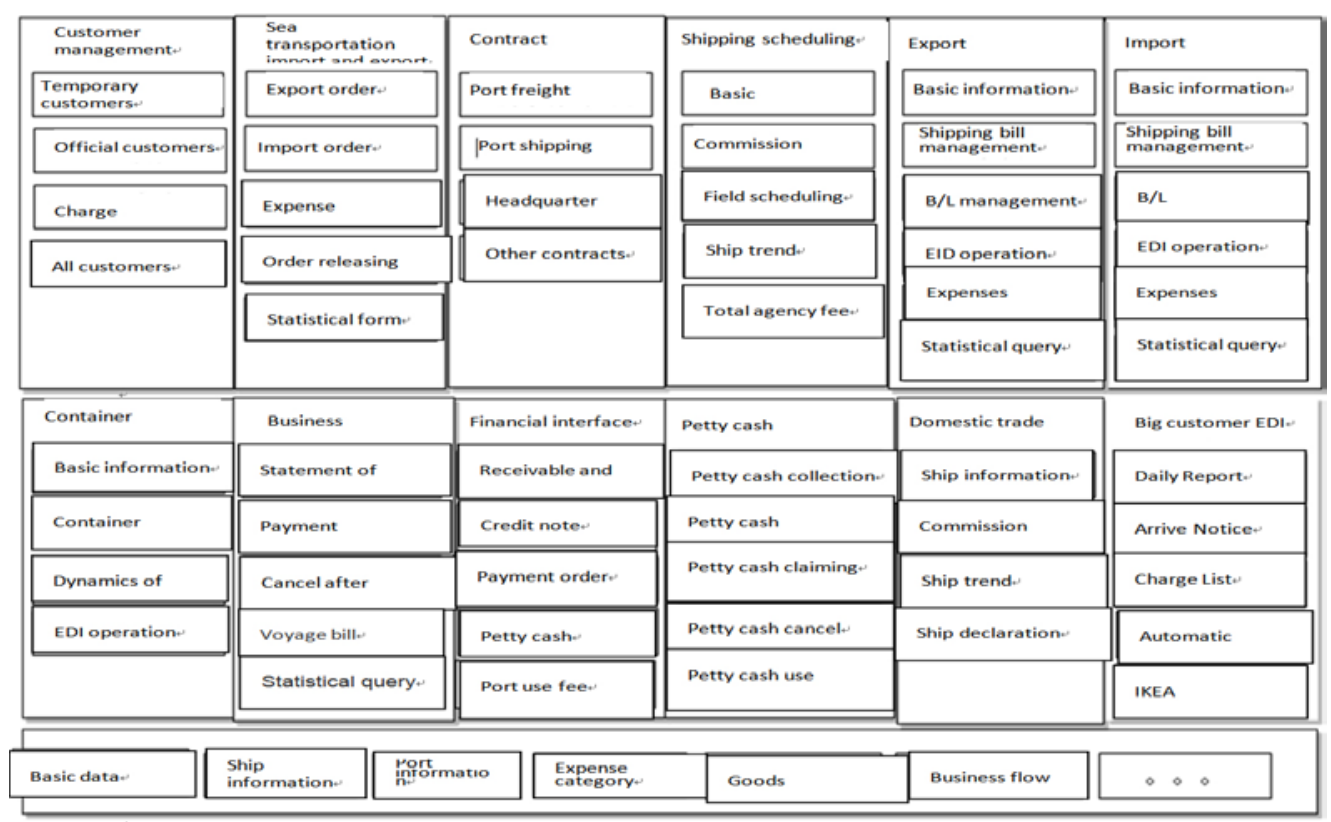

Figure 2. Major Module Diagram

In considerations of the expansibility and universality of the shipping agency and freight forwarding platform, loosely-coupled, configurable, and modular design method was employed to design the system. Figure 2 shows the major module diagram of the system, as shown by which, the platform totally has 12 function modules including customer management, ocean import and export, contract management, shipping scheduling, export documentation, import documentation, container management, business settlement, financial system, etc. The following area only the descriptions on major function modules:

1) Customer management: aiming at different types of customers, provide functions such as customer material maintenance, customer visit planning, customer credit rating management, and so on.

2) Ocean import and export: comprise functions of information processing and receipt processing during the process from inquiry (or accepting a commission) to releasing of cargos in import business operation, and in various links from accepting a commission to issuing a bill of load in an export business.

3) Contract management: provide functions of inputting, maintaining, searching, printing, and reminding the contracts of freight forwarder, shipping agency, headquarter, and other departments.

4) Shipping scheduling: provide functions of declaring ships arriving at the port, tracking a ship's entering and leaving the port, and recording the disbursements and agency fees of a ship incurred by its entering, staying in, and leaving the port.

5) Export documentation: provide functions of accepting the commission of shipowning enterprises, accepting customers' booking, finishing making documentations such as the bill of loading, shipping bill, and so on, sending the customs, ship-owning company, and destination port the shipping bill message, accepting, inputting, examining, modifying, deleting, storing, and managing relevant documentations involved in the import process of containers, carrying out charge list maintenance, and so on. 
6) Import documentation: provide functions of accepting, examining, modifying, deleting, storing, and managing relevant documentations involved in the container import and export process of containers, and so on.

7) Container management: provide functions of controlling the picking up and releasing of containers

8) Business settlement: comprise functions of settling business transaction expenditures, examining the fees incurred in shipping agency businesses, producing bills of account receivable and account payable, invoicing, and so on.

\subsection{Application of Collaborative Management in Shipping Agency and Freight Forwarding Management Platform}

From the constituent elements of Collaborative management, the shipping agency and freight forwarding management platform based on Collaborative management can help the enterprises to share information effectively and achieve unified and centralized management by focusing on the four key elements, i.e., "people, information, procedure, and application", in order to bring convenience to concentrate more on innovation and services. Wherein, Collaborative management is embodied mainly in people synergy, information synergy, procedure synergy, and application synergy;

1) People synergy: a convenient and fast communication mode is provided to the cooperative work of staffs of all modules by taking e-mail, instant message, etc., as the communication tools of the platform.

2) Information synergy: centralized data storage and data integration is the major feature of shipping agency and freight forwarding management platform, which completely supports EDI and seamless data exchange of heterogeneous systems, and can not only share business information timely and accurately within a company by the report center and basic data to reduce the operation cost, but also provide the marine bureau, port, dock, border defense, health quarantine, pilotage, towboat, etc., with complete, timely, and accurate data by the EDI platform to improve the customer service level.

3) Procedure synergy: the platform applies SOA (service-oriented approach) to analyze and decompose the shipping agency and freight forwarding business procedures, define and extract major business operations in a modular manner, and achieve the business procedure synergy between the subsidiaries and headquarter.

4) Application synergy: data interfaces, application programs, and web service management are designed for external applications, which guarantees the optimization and integration of different application systems of the headquarters, subsidiary, and ship owner, and therefore saves the operating cost and improves the management efficiency of the headquarter. In addition, special system interfaces are also set to fully share financial data in different platform systems.

From the internal and external relationship of an enterprise, the shipping agency and freight forwarding management platform based on Collaborative management embodies mainly in the synergy between the headquarters' control and subsidiary's operations, and that between the enterprise and external institutes:

1) Synergy between the headquarters' control and subsidiary's operations: such synergy is embodied mainly in that different departments shall guarantee the smooth running of the business procedure at different levels. The subsidiary is responsible for the daily concrete 
operations of shipping agency or freight forwarding businesses by the concrete business module in the platform; the headquarter takes charge of supervising and administrating the operating procedure from a strategic management height through data sharing and the report center module, and is fully authorized to control the core businesses, such as key customers management, contract management, etc., in the group businesses.

2) Synergy between enterprise and external institutes: such synergy is embodied mainly in the exchange of internal and external data. Through the EDI platform, shipping agency enterprises and freight forwarding enterprises are capable of sharing information with external organizations and institutes such as the marine bureau, the port, and the dock, etc., to improve the data manipulation efficiency; moreover, data sharing can also realized between the ship owner system and enterprises through developing the special interface for the ship owner system.

\section{Application Cases}

Combining the above-mentioned research results and through two years' development, the shipping agency and freight forwarding management platform based on Collaborative management is applied in the China Shipping Agency Co., Ltd. Figure. 3(A) is the main interface of the platform and Figure. 3(B) is an operator using the export documentation function. Table 1 outlines the general condition of China Shipping Agency after the management platform is launched. 58 ports apply the system which has 21 system modules, covers the above-mentioned 12 major modules in term of business scope, and is provided with 790 process plates, 219 EDIs, and 132 report forms. Table 2 shows the comparison of data before and after the platform is launched. Obviously, the numbers of the total orders and the total containers, as well as the numbers of the orders from and containers of the top ten customers are all increased by 10\%-25\% during the period from January to August 2011 on a year-on-year basis. The use of the platform standardizes and simplifies the business operation procedure, brings about convenient, accurate, and timely data sharing, promotes the integration of management and control by the headquarter, enhances the operating efficiency and customer service level of China Shipping Agency, effectively realizes people synergy, information synergy, procedure synergy, and application synergy, and fulfills the operating requirements of large public shipping agency and freight forwarding enterprises. In addition, the platform achieves the integration of business and finance, improves the serviceability of

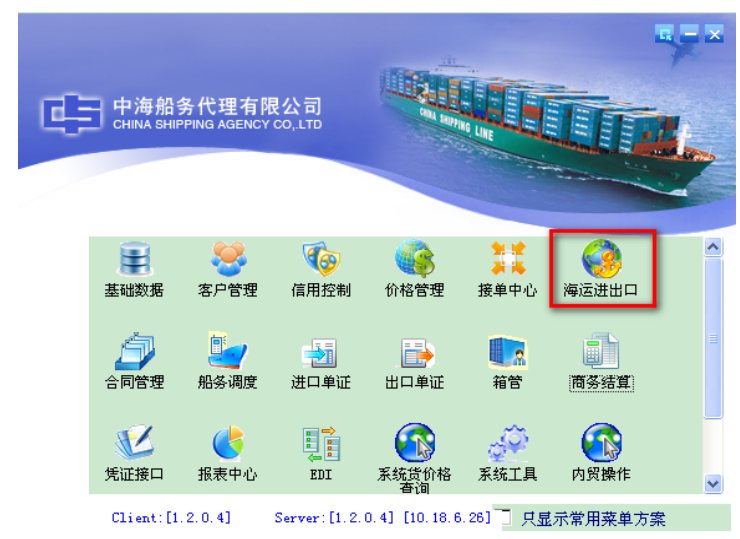

(a) Front UI of System Platform

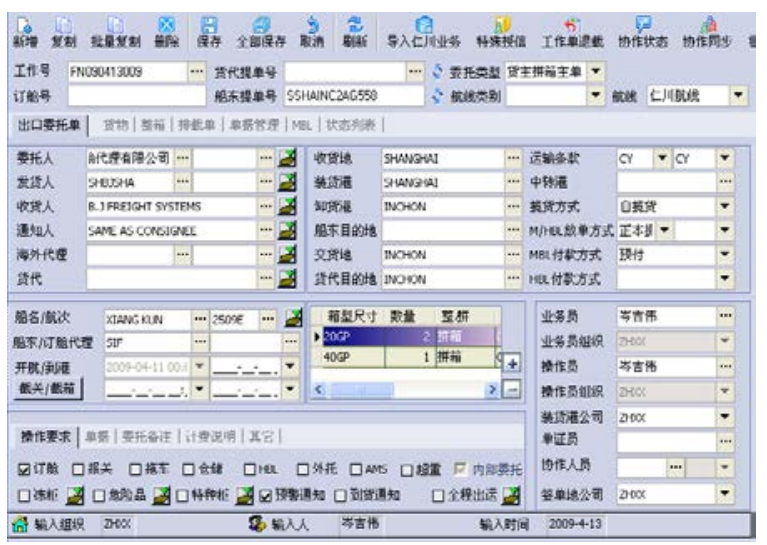

(b) UI of Export Documentation Function

Figure 3. Screenshots of an SFMP Application 
information by sharing the dynamic information in aspects of business and finance with authorized users timely and accurately during the operation process, reduces the operational risks of enterprises by, aiming at different business procedures and systems, setting operation controls at different levels, establishing the management and analysis model and warning mechanism for each level to give risk alarms to the management layer, improves the customer service quality by providing high-quality services to customers based on the integrated and unified data platform, achieving one-stop services, and offering differentiated services to different customers through customer subdivision. Currently, the platform has passed the acceptance inspection of the construction unit, finished the function test by shanghai software center, and applied for the science progress award of shanghai municipality.

\section{Table 1. Generation Condition of China Shipping Agency after the Platform is} Launched

\begin{tabular}{|lc|}
\hline System mode: & integrated unified business system \\
Number of ports using the system: & 58 \\
Number of system modules: & 21 \\
Business scope covered by the system: & support operations of ship agency and freight \\
forwarding, such as booking, documentation, container management, ship commission, business \\
settlement, EDI, report form, financial interface and so on. \\
Number of process plates: & 790 \\
Number of EDIs: & 219 \\
Number of report forms: & 132 \\
\hline
\end{tabular}

Table 2. Data Comparison after the Platform is Launched

\begin{tabular}{|l|l|l|}
\hline Comparison item & January to August 2010 & January to August 2011 \\
\hline Number of orders & 39,000 bills & 44,000 bills \\
\hline Number of containers & 176,000 TEU & 214,000 TEU \\
\hline $\begin{array}{l}\text { Number of orders from top } \\
\text { ten customers }\end{array}$ & 16,000 bills & 2,000 bills \\
\hline $\begin{array}{l}\text { Number of containers of top } \\
\text { ten customers }\end{array}$ & 320,000 TEU & 350,000 TEU \\
\hline $\begin{array}{l}\text { Note: TEU takes the 20-feet container as the international measurement unit and is also called } \\
\text { twenty feet equivalent unit. }\end{array}$ \\
\hline
\end{tabular}

\section{Conclusion}

Shipping agency and freight forwarding management platform is not only a crucial platform for shipping enterprises to carry out businesses, but also a technical guarantee for service efficiency improvement. Aiming at the problems faced by shipping enterprises currently, such as low efficiency in resource allocation, difficulty in integration management of headquarter, and difficulty to guarantee the accuracy and timeliness of data sharing, this study, based on Collaborative management theory and IT technology, has constructed a shipping agency and freight forwarding management platform in allusion to international container shipping logistics enterprises, which covers the whole process of production, marketing, and management of sea transportation container liners. The platform development and construction closely focus on the four core elements in Collaborative management, i.e., people, information, process and application, with the concept of Collaborative management running through the whole process. The practical application case indicates that the platform can increase the operation efficiency by $10 \%-25 \%$, simplify and standardize the actual operation procedure, promote the information sharing among different organizations and 
systems, and improve the synergy level within enterprises. Therefore, the management platform may be further promoted to other shipping agency companies and freight forwarding companies to enhance the overall operation level of domestic shipping companies and promote their overall competitiveness in international and domestic shipping markets.

\section{Acknowledgements}

This work was supported by research program "Management Platform Construction of China Shipping Agency" of Shanghai Science and Technology Committee; Project No. 10dz1511200. This work was also supported by Shanghai municipal soft science research project No.13692106600.

\section{References}

[1] M. Jungong, W. Zhiqiang and L. Laiyi, International Shipping Agency and Container Freight Forwarding Businesses, International Business and Trade Publishing House, Beijin, (2003).

[2] C. Qingsheng, "Design and Implementation Based on Digital Logistics Technology and Shipping Management System”, Journal of Zhejiang Wanli University, vol. 21, no. 5, (2008).

[3] L. Hong, “Application of Unified Modeling Language in Shipping System”, Transportation and Computer, vol. 18, no. 3, (2000).

[4] G. Luyang and S. Yang, "Study on Freight Forwarding Information System”, Logistics Technology, vol. 2, (2009).

[5] Q. Bo and Y. Jinshan, "Solution to Construction of Large Freight Forwarding System”, Journal of Huaqiao University (Natural Science Edition), vol. 30, no. 6, (2009).

[6] L. Liqing, L. Hai and L. Xudong, "Implementation of Single Piece Small-lot Production Management System Based on Collaborative Management”, Manufacturing Automation, vol. 33, no. 9, (2011).

[7] Y. Jia, "Study on Network Logistics Collaborative Management Support System Using ASP for Mediumand Small-size Enterprises”, Modern Manufacturing Engineering, vol. 8, (2010).

[8] D. Dong, "Synergy, Collaborative Management, and Collaborative Management System", Modern Management Science, vol. 2, (2008).

[9] D. Dong, “Collaborative Management System”, Tsinghua University Press, Beijing, (2008).

\section{Authors}

Wu Zhongdai (1976-), male, born in Jiangsu, senior engineer, doctoral candidate, specialized in business management

Ye Minghai (1961-), male, born in Shanghai, professor, doctoral advisor, specialized in business management

Wang Yinyin (1983-), female, born in Zhejiang, doctoral candidate, specialized in business management

Jin Liu(1975-), male, born in Sichuan, associate professor, specialized in software engineering 